$\xi=$ 原

\title{
Evaluation of the efficacy of a locally formulated antiseptic, for the control of disease-causing microorganisms
}

\author{
Anthonia, E. Eseyin ${ }^{1}$ *, Benjamin, O. Omale ${ }^{1}$, Juliet, D. Dodo ${ }^{1}$ \\ ${ }^{1}$ Department of Chemistry, University of Jos, Nigeria \\ *Corresponding author E-mail: eseyinae@gmail.com
}

\begin{abstract}
An antiseptic (sample A) was locally formulated. Its efficacy on the following micro-organisms; E.Coli, staphylococcus, streptococcus and bacillus species was evaluated and compared with that of Dettol and Septol. Sample A was established to be a cheap and effective antiseptic, which is capable of competing favourably with those in the Nigerian market. The Minimum Inhibitory Concentration (MIC) and Minimum Bactericidal Concentration (MBC) indicated that Sample A had a similar efficacy with Dettol. The P-value of the MIC results for samples A, Dettol and Septol were 0.004, 0.268 and 0.080 respectively, while the P-value of the MBC results were 0.450 , 0.077 and 0.043 respectively. The standard errors of the mean were $0.079,0.072$ and 0.086 for sample A, Dettol and Septol respectively.
\end{abstract}

Keywords: Antiseptic; Chloroxylenol; Micro-Organism; Bactericidal and Inhibitory.

\section{Introduction}

An antiseptic is a chemical agent that slows or stops the growth of micro-organisms on external surfaces of the body and helps to prevent infections. Antiseptics should be distinguished from antibiotics, which destroy micro-organisms inside the body, and from disinfectants, which destroy micro-organisms found on inanimate (non-living) objects. However, antiseptics are often referred to as skin disinfectants (Ngan 2005).

Antiseptics are crucial in the prevention of wound infections. Nosocomial infections or health care associated infections occur in patients under medical care. These infections occur worldwide, both in developed and developing countries (Khan et al. 2017).

Antiseptics and disinfectants are used extensively in hospitals and other health care centers to control the growth of microbes on both living tissues and inanimate objects. They are essential parts of infection control practices and aid in the prevention of nosocomial infections (Larson \& Morton 1991).

There is however, a common problem in the selection of disinfectants and antiseptics because different pathogens vary in their responses to different antiseptics or disinfectants (Russell 1996). Antiseptics are chemical compounds, mainly added to water used for bathing, laundry, mouth washing, wound dressing and other domestic activities such as general house cleaning (Chapman 2003). Antiseptics are used to control or reduce the growth of pathogenic microbes found on human body.

Many antiseptics in the Nigerian market today, have varying degrees of efficacy; which may be attributable to their active ingredients. Most of the antiseptics contain one of the following compounds: chlorhexidine, phenol, chloroxylenol and cetylpyridinium chloride (CPC). All, with the exception of the mouth wash, are applied externally to prevent the proliferation of microbial population (Giuliana et al. 1997).

Some of the different types of antiseptics in the Nigerian market are; Dettol, Septol, Savlon, Roberts and Izal. For antiseptics to function optimally however, several factors, majorly, the concentration of the antiseptic has to be taken into consideration. It is known that there is an exponential relationship between potency and concentration of an antimicrobial agent (Gorman 2007, Lamikanra 2010). This means that the more concentrated an agent is, the greater the efficacy and the shorter the time necessary to destroy the micro-organisms it is intended for. Nonetheless, due to the possibility of toxicity, the concentration of antiseptics must be strictly controlled (Gorman 2007).

A very common problem is the selection of antiseptics because different pathogens vary in their responses to different antiseptics. Antiseptics are widely used in homes and health care settings for various purposes including disinfection of skin, objects and equipment, as well as environmental surfaces. Micro-organisms are continually acquiring resistances to the current antiseptics and the need to formulate new ones cannot be over emphasized. Despite the number of antiseptics in the market today, micro-organisms still remain a threat to humans. Therefore there is a need to formulate an antiseptic that is very effective and affordable for the Nigerian public.

This study aims at locally formulating and evaluating the efficacy of a new, effective and affordable liquid antiseptic, using Chloroxylenol as an active ingredient and also, to compare the efficacy of the antiseptic formulated, with some of those in the Nigerian market. 


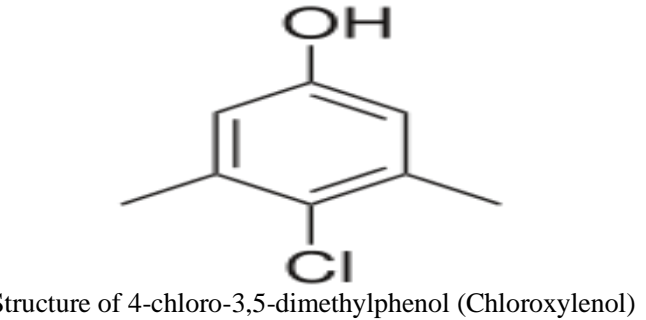

\section{Methods}

The materials used for this study include: Texapon, isopropanol, phenol, top pan balance, micropipettes, beakers, incubator, micro dilution plates, distilled water, wire loop, cotton wool, foil paper, nutrient broth/agar, petri dishes, spirit lamp, autoclave, air oven, conical flasks.

\subsection{Sample collection}

Antiseptics commercially available in the Nigerian markets were surveyed and two of the most used ones (Dettol and Septol) were sampled and purchased from Jos Terminus main market, Jos North Local Government area of Plateau State, Nigeria. The main purpose of this selection was to compare their efficacies with that of the study sample. Chloroxylenol, castor and pine oils were sampled and purchased from Katako market, Jos North Local Government area of Plateau State Nigeria.

\subsection{Formulation of study sample (Nanzip 2020)}

Phenol $(1000 \mathrm{ml})$ was gently poured into a beaker and $50 \mathrm{ml}$ texapon was dissolved in it. Fifty ml pine oil was then added and stirred properly, after which, $50 \mathrm{ml}$ chloroxylenol was also added and stirred. Isopropanol $(50 \mathrm{ml})$ and $50 \mathrm{ml}$ castor oil were then added and stirred properly. Finally, $250 \mathrm{ml}$ of distilled water was poured into the content and stirred vigorously. The formulated antiseptic, formed a milky emulsion of oil droplets when diluted in water.

\subsection{Dilution of the antiseptics}

$5 \mathrm{ml}$ of each of the samples A, B and C (sample A= study sample, B = Dettol and C = Septol were diluted into 95ml of distilled water and mixed thoroughly

\subsection{Preparation of media (Sagar 2017)}

Eight grams of agar was suspended in one liter of distilled water in a beaker, it was then well mixed and dissolved by heating with frequent agitation. This was boiled for one minute until complete dissolution and then sterilized in an autoclave at $121^{\circ} \mathrm{C}$ for 15 minutes. The prepared medium was dispensed into petri dishes and allowed to cool and solidify

\subsection{Source of micro-organisms}

Microorganisms; (E.Coli, staphylococcus, streptococcus and bacillus species) were obtained from the Pharmacy microbiology laboratory; University of Jos, Jos North Local Government area of Plateau State, Nigeria. They were isolated and then, stored in the refrigerator for further research work.

The minimum bactericidal concentration $(\mathrm{MBC})$ is the lowest concentration of an antibacterial agent required to kill a particular bacterium. It can be determined from broth dilution. Minimum inhibitory concentration (MIC) tests were conducted, by sub culturing to agar plates that do not contain the test agent (Maris 1995).

The MBC is identified by determining the lowest concentration of antibacterial agent that reduced the viability of the initial bacterial inoculum by $99.9 \%$. The MBC is complementary to the MIC; whereas the MIC test demonstrates the lowest level of antimicrobial agent that inhibits growth, the MBC demonstrates the lowest level of antimicrobial agent that results in microbial death. This means that even if a particular MIC shows inhibition, plating the bacteria onto agar might still result in organism proliferation because the antimicrobial did not cause death. (Tripathi 2013).

\subsection{MIC and MBC assay (www emerypharma.com)}

Two-fold serial dilutions of sample A, together with one quality control (QC) antibiotic were placed in plates. The inoculum was created by taking a few colonies from an agar plate with a sterile swab. A McFarland standard was prepared and diluted into media. $0.5 \mu 1$ of the inoculum (E.Coli), was dispensed into the micro dilution plates with the serial diluted test compounds, thoroughly homogenized, and incubated at $37^{\circ} \mathrm{C}$ for 24 hours to enhance the growth of the micro-organism. The micro dilution plates were then read, to determine the MIC values. A portion of each was placed well on an appropriate agar medium, which was then incubated and colonies checked to determine the MBC values. The procedure was repeatable for sample B (Dettol) and samples C (Septol), each with (staphylococcus, streptococcus and bacillus species) respectively.

\section{Results}

The results obtained from the microbial analysis carried out on four different micro-organisms, to compare sample A with Dettol and Septol were analysed and tabulated. 
The results for Sample A for both Minimum Inhibitory Concentration (MIC), and Minimum Bactericidal Concentration (MBC) are shown in the first part of the tables, followed by the MIC and (MBC) of sample B and lastly that of sample $\mathrm{C}$ as tabulated below:

Table 1: Minimum Inhibitory Concentration (MIC) of Sample A

\begin{tabular}{lllll}
\hline & & Frequency & Percentage & Cumulative percentage \\
\hline Valid & Positive & 9 & 27.3 & 27.3 \\
& Negative & 24 & 72.7 & 100.0 \\
& Total & 33 & 100.0 & \\
\hline
\end{tabular}

Table 2: Minimum Bactericidal Concentration (MBC) of Sample A

\begin{tabular}{lllll}
\hline & & Frequency & Percentage & Cumulative percentage \\
\hline Valid & Positive & 20 & 60.6 & 60.6 \\
& Negative & 13 & 39.4 & 100.0 \\
& Total & 33 & 100.0 & \\
\hline
\end{tabular}

Table 3: Minimum Inhibitory Concentration (MIC) of Sample B

\begin{tabular}{lllll}
\hline & & Frequency & Percentage & Cumulative percentage \\
\hline Valid & Positive & 7 & 21.2 & 21.2 \\
& Negative & 26 & 78.8 & 100.0 \\
& Total & 33 & 100.0 & \\
\hline
\end{tabular}

\begin{tabular}{lllll} 
& \multicolumn{4}{c}{ Table 4: Minimum Bactericidal Concentration (MBC) of Sample B } \\
\hline & & Frequency & Percentage & Cumulative percentage \\
\hline Valid & 20 & 60.6 & 60.6 \\
& Positive & 13 & 39.4 & 100.0 \\
& Negative & 33 & 100.0 & \\
& Total & & &
\end{tabular}

Table 5: Minimum Inhibitory Concentration (MIC) of Sample C

\begin{tabular}{lllll}
\hline & & \multicolumn{4}{c}{ Table 5: Minimum } & Crequency & Percentage & Cumulative percentage \\
\hline \multirow{2}{*}{ Valid } & Positive & 13 & 39.4 & 39.4 \\
& Negative & 20 & 60.6 & 100.0 \\
& Total & 33 & 100.0 & \\
& & &
\end{tabular}

Table 6: Minimum Bactericidal Concentration of Sample C

\begin{tabular}{lllll}
\hline & & Frequency & Percentage & Cumulative percentage \\
\hline Valid & Positive & 18 & 54.5 & 54.5 \\
& Negative & 15 & 45.5 & 100.0 \\
& Total & 33 & 100.0 & \\
\hline
\end{tabular}

Table 7: Effectiveness of Sample A (MIC) Results

\begin{tabular}{lllllll}
\hline & \multicolumn{7}{c}{ Table 7: Effectiveness of Sample A (MIC) Results } \\
\hline & E. COLI & STAPH. & STREPT. & BACILLUS & Total \\
Positive & 5 & 2 & 2 & 0 & 9 \\
Total & 1 & 5 & 8 & 10 & 24 \\
\hline $\mathrm{x}^{2}=13.530, \mathrm{df}=$ 3 P-value 0.004. & 6 & 7 & 10 & 10 & 33 \\
\hline
\end{tabular}

Table 8: Effectiveness of Sample A (MBC) Results

\begin{tabular}{|c|c|c|c|c|c|c|}
\hline & & E. $C O L I$ & STAPH. & STREPT. & BACILLUS & Total \\
\hline & Positive & 2 & 4 & 7 & 7 & 20 \\
\hline & Negative & 4 & 3 & 3 & 3 & 13 \\
\hline Total & & 6 & 7 & 10 & 10 & 33 \\
\hline
\end{tabular}

$\mathrm{x}^{2}=2.644, \mathrm{df}=3$, P-value $=0.450$.

Table 9: Sample B (MIC) Results

\begin{tabular}{lllllll}
\hline & E. COLI & STAPH. & STREPT. & BACILLUS & Total \\
\hline & Positive & 3 & 1 & 2 & 1 & 7 \\
Total & 3 & 6 & 8 & 9 & 26 \\
\hline$x^{2}=3.937$, Negative & 6 & 7 & 7 & 10 & 10 & 33 \\
\hline
\end{tabular}

$\mathrm{x}^{2}=3.937, \mathrm{df}=3$, P-value $=0.268$.

Table 10: Sample B (MBC) Results

\begin{tabular}{lllllll}
\hline & E. COLI & STAPH. & STREPT. & BACILLUS & Total \\
\hline & Positive & 1 & 4 & 8 & 7 & 20 \\
Total & 5 & 3 & 2 & 3 & 13 \\
\hline
\end{tabular}

$\mathrm{x}^{2}=6.832, \mathrm{df}=3$, P-value $=0.077$.

Table 11: Sample C (MIC) Results

\begin{tabular}{lllllll}
\hline & E. COLI & STAPH. & STREPT. & BACILLUS & Total \\
\hline & Positive & 5 & 2 & 2 & 4 & 13 \\
Negative & 1 & 5 & 8 & 6 & 20 \\
Total & 6 & 7 & 10 & 10 & 33 \\
\hline $\mathrm{x}^{2}=6.772, \mathrm{df}=3$, P-value $=0.080$. & & & &
\end{tabular}

Table 12: Sample C (MBC) Results

\begin{tabular}{llllll}
\multicolumn{7}{c}{ Table 12: Sample C (MBC) Results } \\
\hline & E. COLI & STAPH. & STREPT. & BACILLUS & Total \\
\hline Positive & 2 & 2 & 9 & 5 & 18
\end{tabular}




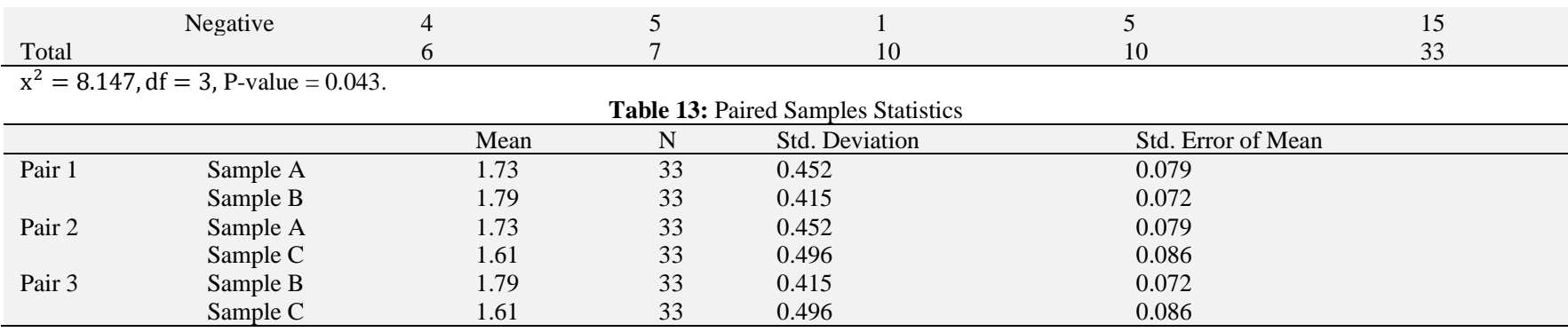

Table 14: Paired Sample Test

\begin{tabular}{lllll}
\hline & & T & df & Sig. (2-tailed) \\
\hline Pair 1 & Sample A - Sample B & -1.000 & 32 & 0.324812713651087 \\
Pair 2 & Sample A - Sample C & -2.101 & 32 & 0.043615703275240 \\
Pair 3 & Sample B - Sample C & 2.667 & 32 & 0.011914159541709 \\
\hline
\end{tabular}

\section{Discussion}

The organisms isolated were established pathogens, which may have been present on the surfaces of inanimate objects and water, which may pose serious public health risks. Environment contamination is recognized as a source of infection and as such, there is a need to understand the role of environmental surface disinfection in disease control.

The appearances of cloudy zones of inhibition on the microbial growth were indications of the efficacy of the disinfectants, on the inhibition of bacteria growth with larger zone of inhibition, indicating the antimicrobial is more potent (www.microchemlab.com). The new locally formulated antiseptic (sample A), a chloroxylenol was used as an antiseptic formulation and a bactericidal (to remove or kill micro-organisms).

Table 1 shows results for the minimum inhibition concentration (MIC) of sample A, on the microorganisms employed for this study. Nine of the plates show positive growth out of 33 plates while 24 plates show negative (inhibited) growth. Table 2 indicates the minimum bactericidal concentration (MBC).

Table 3 indicates the minimum inhibition concentration of sample B, on the organisms. Seven of the plates show positive growth out of 33 plates and 26 negatives. Table 4, which is the minimum bactericidal concentration, shows 20 positive growths while 13 were bacteriostatic, out of 33 plates.

Table 5 indicates the efficacy of sample $\mathrm{C}$, on the micro-organisms employed for this study. Out of 33 plates, 13 plates show positive growth, while 20 show negatives in the case of minimum inhibition concentration. In Table 6 , the minimum bactericidal concentration of sample $\mathrm{C}$ was that out of 33 plates, 18 were inhibited and 15 were killed or removed.

From the results, Tables 1, 3 and 5 indicate the (MIC) of sample A, sample B and sample C. The positive indicates the number of plates in which the micro-organism survived, while the negative indicates the number of plates in which the micro-organisms were killed or inhibited. Tables 2, 4 and 6 show the (MBC). This test was carried out to check if the micro-organisms, in the number of plates, showing negative (MIC) were actually killed or not. Therefore, the number of plates, showing positive, in the case of (MBC) is more important, indicating that the micro-organisms have been completely eliminated. The results of (MIC) and (MBC) indicated that Sample A had a similar effect with Dettol. However, Septol had reduced effect on the micro-organisms.

Tables 7, 9 and 11 present the MIC results of the efficacies of samples A, B and C on the micro-organisms (E.coli, Staphilococcus, Streptococcus and Bacillus species) employed for this study. The total numbers of plates used are indicated. Positive indicates those plates that there was growth after $24 \mathrm{hrs}$ while negative indicates those inhibited. The P-values of these results were; $0.004,0.268$ and 0.080 respectively.

Tables 8, 10 and 12 show the MBC results of the three samples; A, B and C. The total number of plates used is also indicated. The positive sign indicates the micro-organisms that have been killed or eliminated, while the negative indicates the ones that were only inhibited. The P-values of the three tables were; $0.450,0.077$ and 0.043 respectively.

Tables 13 and 14 compared the results of the paired sample tests. From the results of the standard error of mean; $(0.079$ for sample A, 0.072 for Dettol and 0.086 for Septol), it is clear that there is a big difference between Samples A and C as well as samples B and C. However, samples A and B have similar results and the difference between them is negligible. Since sample A, a phenolic compound has a similar effect in the prevention of the micro-organisms used in this study, sample A is capable of competing favourably with the best antiseptics in the Nigerian market today.

Dettol is also a chloroxylenol and is bactericidal. As a phenolic compound, its major mechanism of action would be on microbial membrane (French 2006). Septol is a hexachlorophene and as a bis-phenol, its mode of action is to inhibit the membrane bound part of the electron transport chain (McDonnell \& Russell 2001) and might have secondary effect at high concentrations. From this study, samples A and sample B, that are phenolic compounds show similar results. However, Septol, a bis-phenol compound, showed fewer efficacies on micro-organisms.

\section{Conclusion}

Sample A has been established to be a cheap and effective antiseptic. Since sample A, a phenolic compound has a similar effect in the elimination of the micro-organisms, used in this study. Sample A is capable of competing favourably with the best antiseptics that are currently being sold in the Nigerian market.

Dettol is also a chloroxylenol and bactericidal. As a phenolic compound, its major mechanism of action would be on microbial membrane. Septol is a hexachlorophene and as a bis-phenol, its mode of action is to inhibit the membrane bound part of the electron transport chain, and might have secondary effect at high concentrations. It has been shown that E. Coli (gram negative) showed greater resistance to all the antiseptics used in this study. It can survive at manufacturer's stated dilution for Samples B and C, used for this study. One of the implications of this is that, the pathogens can be selective and gradually displace sensitive strains. Instructions for dilutions of anti- 
septics should therefore, consider the effects of dilutions on the antimicrobial activities of the antiseptics in order to prevent antiseptic failure.

\section{References}

[1] Ngan V (2005) What is an antiseptic? Available at: https://www.dermnetnz.org/topics/antiseptic/. Accessed April 25, 2020

[2] Khan HA, Baig FK \& Mehboob R (2017) Nosocomial infections: Epidemiology, prevention, control and surveillance Asian Pacific Journal of Tropical Biomedicine 5, 478-482. https://doi.org/10.1016/j.apjtb.2017.01.019.

[3] Larson EL \& Morton HE (1991) Alcohols. In: Block, S.S., Ed., Disinfection, Sterilization, and Preservation, 4th Edition, Lea and Febiger, Philadelphia, PA, 191-203. Available at: https://www.scirp.org. Accessed April 25, 2020.

[4] Russell AD (1996) Activity of biocides against mycobacteria J. Appl. Bacteriol. Symp. Suppl, 81, 87-101. https://doi.org/10.1111/j.13652672.1996.tb04602.x.

[5] Chapman JS (2003) Disinfectant resistance mechanisms, cross-resistance, and co-resistance International Biodeterioration \& Biodegradation 51, 271-276. https://doi.org/10.1016/S0964-8305(03)00044-1.

[6] Giuliana G, Pizzo G, Milici M, Musotto GC \& Giangreco R (1997) In vitro antifungal properties of mouth rinses containing antimicrobial agents Journal Periodontol 68, 729-733. https://doi.org/10.1902/jop.1997.68.8.729.

[7] Lamikanra A (2010) Essential Microbiology for Students and Practitioner of Pharmacy, Medicine and Microbiology 2nd Edn. Lagos: Amkra books; 406.

[8] Gorman SP (2007) Chemical Disinfectants, Antiseptics and Preservatives In book: Hugo and Russell's: Pharmaceutical Microbiology, Seventh Edition. Available at: https:// www.wiley.com/go/denyer/microbiology. Accessed April 27, 2020

[9] Nanzip BN (2020) Formula for Homemade Antiseptic or Disinfectant. Available at: https:// jotsrcoll.com. Accessed April 1, 2020.

[10] Sagar (2017) Nutrient Agar and Nutrient Broth: Composition, Preparation and Differences. Available at: https:// www. LabMal.com. Accessed April 10, 2020.

[11] Maris P (1995) Modes of action of disinfectants Review Scientific Technique 14, 47-55. https://doi.org/10.20506/rst.14.1.829.

[12] Tripathi KD (2013) Essentials of Medical Pharmacology (7th ed.). New Delhi, India: Jaypee Brothers Medical Publishers ISBN 9789350259375. https://doi.org/10.5005/jp/books/12256.

[13] Minimum Inhibitory Concentration (MIC) and Minimum Bactericidal Concentration (MBC) Assay. Available at: http://www emerypharma.com. Accessed January 18, 2020.

[14] Zone of Inhibition Test for Antimicrobial Activity. Available at: http://www.microchemlab.com. Accesed June 6, 2020.

[15] French GL (2006) Bactericidal agents in the treatment of MRSA infections-the potential role of daptomycin. Journal of Antimicrobial Chemotherapy, 56 1107-1117. https://doi.org/10.1093/jac/dkl393.

[16] McDonnell G \& Russell AD (2001) Antiseptics and Disinfectants: Activity, Action, and Resistance Clinical Microbiology Reviews 14, 227. PMCID: PMC88971. https://doi.org/10.1128/CMR.14.1.227-227.2001. 